\title{
Simulation Analyses of Two On-Ramp Lane Arrangements
}

\author{
Xu Wang ${ }^{1} \cdot$ Xiao-Bo $\mathrm{Qu}^{2}(1) \cdot \mathrm{Pan}_{\mathrm{Li}}{ }^{3}$ \\ Received: 9 February 2018 / Revised: 13 June 2018 / Accepted: 28 August 2018 / \\ Published online: 1 October 2018 \\ (c) The Author(s) 2018
}

\begin{abstract}
Ramps are vital pieces of infrastructure connecting city traffic networks to freeways. The performance of a ramp is to some extent determined by the on-ramp lane arrangement. In this paper, our primary aim is to evaluate the performance in terms of travel time and vehicle emissions for two on-ramp lane arrangements: added lane and zip merging. We estimate the travel time and $\mathrm{CO}_{2}$ emissions on the basis of the speed, and acceleration of vehicles in accordance with the improved comprehensive modal emission model (CMEM), and then analyse the impacts of traffic volume and heavy goods vehicles (HGVs) on travel time and emissions. The impacts of main road traffic flow on travel time and emissions for the two on-ramp lane arrangements are analysed under scenarios with traffic volumes of 800,1 000,1 200,1 400, 1600 and 1800 vehs/h/lane. Meanwhile, the relationships between travel time, emissions and various proportions of $\mathrm{HGVs}(2 \%, 4 \%, 6 \%, 8 \%$ and $10 \%)$ for both on-ramp lane arrangements are evaluated as well. We eventually present emission contour charts for the two onramp lane arrangements based on the possible combinations of traffic volumes and HGV percentages.
\end{abstract}

Keywords On-ramp lane arrangement · comprehensive modal emission model $(\mathrm{CMEM}) \cdot$ Micro-traffic simulation model $\cdot$ Travel time $\cdot \mathrm{CO}_{2}$ emissions $\cdot$ Traffic volume $\cdot$ heavy goods vehicles (HGVs)

Mathematics Subject Classification 90B20

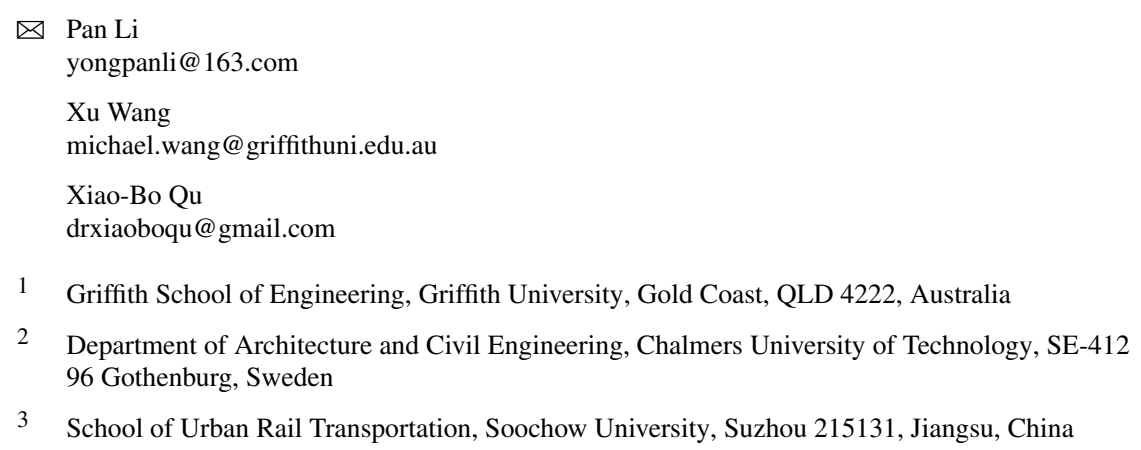




\section{Introduction}

Nowadays, freeways are serving in an increasingly significant role, carrying vehicles safely and efficiently and sustaining traffic at consistently high speeds, in the urban transport system [1]. However, with the increased utilization of freeways, frequent traffic delays have resulted in a loss to travel time and high emissions of carbon dioxide [2]. Therefore, addressing the loss of travel time and environmental pollution due to traffic delays is of utmost concern by traffic agencies [3]. In this regard, optimizing on-ramp lane arrangements is a solution worth being considered by traffic engineers.

There is a relatively extensive literature focusing on the improvements in freeway operation. Among them, many researchers recommended to reduce travel time in the on-ramp adjacent zones through traffic control and freeway geometry upgrade (e.g. [2, 4-9]. Few researches have discussed the impact of on-ramp lane arrangements on freeway operation. In this paper, we will explore the effect. Additionally, due to the correlation between travel time and emissions, the impact of both on-ramp lane configurations on emissions will be also explored. Emissions estimation has been a concern of researchers for decades (e.g. [10, 11]). The existing emissions prediction models can be divided into macroscopic and microscopic models [12]. In the macroscopic world, the emissions for a certain pollutant and a given type of vehicles are typically considered as a function of average speed [13]. Afterwards, the emissions models have been progressively perfected by adding new emission factors and new vehicle classifications. However, the input of single data (the average speed) restricts the accuracy of emissions estimation. Accordingly, scholars devoted themselves to the exploration of microscopic models. In 1996, Barth et al. assessed an engine emissions based on the engine output power and developed the comprehensive modal emissions model (CMEM). Afterwards, Rakha et al. [14] proposed the Virginia Tech microscopic (VT-Micro) energy and emission model in the form of a regression model linking vehicle energy consumption rate and emission rate to the instantaneous speed and acceleration. However, the VT-Micro was only calibrated by light duty vehicles and trucks, which cannot be widely applied. Therefore, we applied the CMEM to predict emissions for the research freeway section.

This paper investigated the impacts of variability of mainline traffic volumes and mainline heavy goods vehicles (HGVs) on travel time and emissions in the investigated road segments fitted with two types of on-ramp lane arrangements. The research could provide traffic engineers with a guideline, regarding how to select a proper on-ramp lane configuration for those road segments with closely spaced on- and off-ramps, in terms of travel time and emissions. The rest of the paper is organized as follows. Section 2 describes the investigated road segment and data collection process. The CMEM is formulated in Sect. 3. Section 4 demonstrates the validity of simulation models. A comparative analysis is carried out in Sect. 5. Section 6 concludes.

\section{Site Description and Data Collection}

As can be seen in Fig. 1, one 800 m bottleneck on Australia Pacific Motorway, in the vicinity of Nerang (a suburb of Gold Coast), was selected as the investigated road 

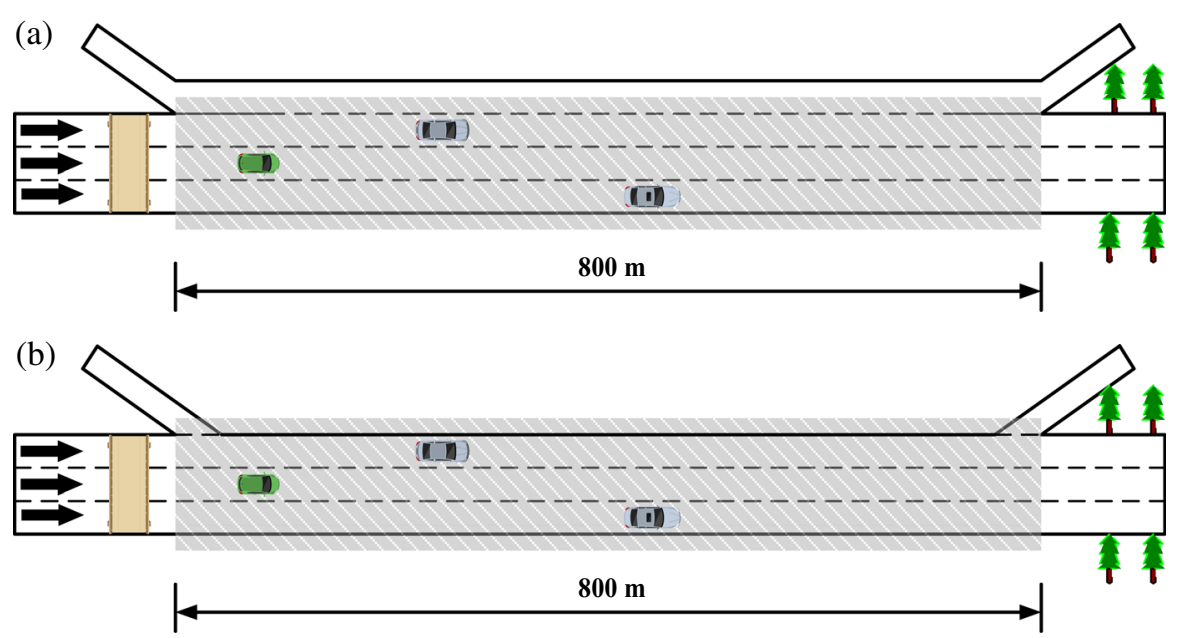

Fig. 1 The investigated road segment fitted with two types of on-ramp lane arrangements. (a) The investigated road segment fitted with added/auxiliary lane; (b) the investigated road segment fitted with zip merging lane

segment, as the local council has been seeking a proper solution to address the recurring congestion in peak hours. The traffic data used for emissions calculation are hard to be collected in the real world [15-17]. As a consequence, we applied VISSIM models to generate traffic data assessing travel time and calculating emissions. Before they were formally used, the parameters in VISSIM need to be calibrated and the simulated data need to be validated with the observed data. Towards this end, the videos were recorded from four different time periods. We extracted traffic volumes and HGVs counts from them for the sake of the development of simulation models. Besides, traffic trajectory data were also retrieved to validate the reliability of simulated traffic data. Table 1 simply aggregates the observed traffic data.

Table 1 The summary of traffic flow at research segment

\begin{tabular}{llll}
\hline Time periods & $\begin{array}{l}\text { Mainline traffic flow } \\
(\text { vehs/h) }\end{array}$ & $\begin{array}{l}\text { Mainline HGVs } \\
\text { (vehs/h) }\end{array}$ & $\begin{array}{l}\text { On-ramp traffic flow } \\
(\text { vehs/h) }\end{array}$ \\
\hline $\begin{array}{l}\text { Morning peak } \\
(7: 00 \text { am-8:00 am) }\end{array}$ & 5478 & $411^{\mathrm{a}}(7.5 \%)$ & $269^{\mathrm{b}}(4.9 \%)$ \\
$\begin{array}{c}\text { Transitional off-peak } \\
(12: 00 \text { pm-1:00 pm) }\end{array}$ & 3405 & $266^{\mathrm{a}}(7.8 \%)$ & $161^{\mathrm{b}}(4.7 \%)$ \\
$\begin{array}{c}\text { Afternoon peak } \\
(4: 00 \text { pm-5:00 pm) }\end{array}$ & 4644 & $341^{\mathrm{a}}(7.3 \%)$ & $242^{\mathrm{b}}(5.2 \%)$ \\
$\begin{array}{c}\text { Night off-peak } \\
(7: 00 \text { pm-8:00 pm) }\end{array}$ & 2427 & $157^{\mathrm{a}}(6.5 \%)$ & $124^{\mathrm{b}}(5.1 \%)$ \\
\hline
\end{tabular}

\footnotetext{
${ }^{\mathrm{a}}$ The proportion of HGVs on freeway main carriageways

${ }^{\mathrm{b}}$ The percentage that on-ramp traffic flow occupies mainline traffic flow
} 


\section{Methodology}

The CMEM has been widely used for the emissions estimates of numerous classes of vehicles, which make up for the usage limitations in the VT-Micro energy and emission model. It can estimate distance-based fuel consumption rates caused by vehicles' driven force, engine friction and air-conditioning. Vehicles' fuel consumption rates are to a great extent dependent upon the instantaneous speeds $(v)$ and accelerations $(a)$. In this research, we simply hypothesize that the instantaneous speed and acceleration for each vehicle is invariable in the $10 \mathrm{~m}$ road segment. We collected all vehicles' instantaneous speeds and accelerations in any $10 \mathrm{~m}$ road segment by means of 80 virtual data collection points set up in VISSIM models. By using Eq. 3.1, the fuel consumption $F(v, a)$ for each vehicle can be calculated in the unit of grams per metre per vehicle. Once the fuel consumption for each vehicle is known, based on the concept of carbon balance [18], the $\mathrm{CO}_{2}$ emissions for each vehicle are calculated as per Eq. 3.2. The summation of $\mathrm{CO}_{2}$ emissions for a certain vehicle in the investigated road segment can be estimated according to Eq. 3.3.

$$
F(v, a)=\frac{\varphi}{\lambda}\left(\sum_{i=0}^{3} \alpha_{i} \cdot v^{i-1}+\beta \cdot a\right),
$$

where the coefficients are given by

$$
\begin{gathered}
\alpha_{0}=\frac{P_{a}}{\eta}, \quad \alpha_{1}=Z g \frac{G+c_{1}}{\eta \varepsilon}+c_{4} K_{0} V \theta\left(r+c_{3} v_{h}^{2}\right), \quad \alpha_{2}=Z g \frac{c_{1}}{c_{2} \eta \varepsilon}-2 c_{3} c_{4} K_{0} V v_{h} \theta, \\
\alpha_{3}=\frac{\rho C_{d} A}{2 \eta \varepsilon}+c_{3} c_{4} K_{0} V \theta \quad \beta=\frac{Z\left(1+e_{0}\right)}{\eta \varepsilon}, \\
E_{\mathrm{CO}_{2}}(v, a)=\gamma_{1} F(v, a)+\frac{\gamma_{0}}{v},
\end{gathered}
$$

where

$$
\begin{gathered}
\gamma_{0}=-\frac{A_{r}\left(\mathrm{CO}_{2}\right) \cdot c_{8}}{A_{r}(\mathrm{C})+\mu}, \quad \gamma_{1}=A_{r}\left(\mathrm{CO}_{2}\right)\left(\frac{1-c_{7}}{A_{r}(C)+\mu}-\frac{c_{5}\left(1-\varphi^{-1}\right)+c_{6}}{A_{r}(\mathrm{CO})}\right), \\
\sum E=\int_{0}^{X} E_{\mathrm{CO}_{2}}(v, a) \mathrm{d} x .
\end{gathered}
$$

In the above three equations, the specific parameter descriptions and values for passenger cars and HGVs can be found in "Appendix". They are complicated to be gathered in the real world. Therefore, in this research, we referred to and cited the parameter values of previous researches. 


\section{Simulation Model Calibration and Validation}

Prior to utilizing VISSIM, the parameters in the simulation model need to be calibrated. Firstly, the geometric characteristics of the investigated site, including the number of through lanes, lane widths, link lengths, and grade were coded in the simulation model by using Google Earth Pro. Secondly, four parameters affecting simulation precision [CC0, CC1, CC2 and the desired lane change distance (DLCD)] were sorted out. Thirdly, we applied genetic algorithm (GA) to find out the best set of values for these four parameters under four different time periods. Table 2 shows the best fitted parameter sets for each time period.

The collative data shown in Table 1 were imported into VISSIM in order to develop four simulation models. To validate the reliability of the calibrated simulation models, the traffic trajectory curves for 20 consecutive vehicles in each time period were, respectively, extracted from the observed videos and the simulated animation and then are illustrated in Fig. 2(a-d). Four types of error tests were conducted to evaluate the differences between the simulated speeds and the observed speeds (e.g. [19-25]. These four error tests are the root mean square error (RMSE), the root mean square percentage error (RMSPE), the mean percentage error (MPE) and Theil's inequality coefficient $(U)$, mathematically represented by,

$$
\begin{aligned}
\text { RMSE } & =\sqrt{\frac{1}{N} \sum_{n=1}^{N}\left(v_{s}^{n}-v_{f}^{n}\right)^{2}}, \\
\mathrm{RMSPE} & =\sqrt{\frac{1}{N} \sum_{n=1}^{N}\left(\frac{v_{s}^{n}-v_{f}^{n}}{v_{f}^{n}}\right)^{2}}, \\
\mathrm{MPE} & =\frac{1}{N} \sum_{n=1}^{N}\left(\frac{v_{s}^{n}-v_{f}^{n}}{v_{f}^{n}}\right),
\end{aligned}
$$

Table 2 Calibrated parameters for each time period

\begin{tabular}{lllll}
\hline Time periods & $\mathrm{CC} 0 / \mathrm{m}$ & $\mathrm{CC} 1 / \mathrm{s}$ & $\mathrm{CC} 2 / \mathrm{m}$ & $\mathrm{DLCD} / \mathrm{m}$ \\
\hline $\begin{array}{l}\text { Morning peak } \\
(7: 00 \text { am-8:00 am) }\end{array}$ & 1.3 & 0.7 & 3.5 & 800.0 \\
$\begin{array}{l}\text { Transitional } \\
\text { off-peak } \\
(12: 00 \mathrm{pm}-1: 00 \mathrm{pm})\end{array}$ & 2.0 & 1.9 & 5.0 & 200.0 \\
$\begin{array}{l}\text { Afternoon peak } \\
\quad(4: 00 \mathrm{pm}-5: 00 \mathrm{pm})\end{array}$ & 1.8 & 1.0 & 4.1 & 250.0 \\
$\begin{array}{l}\text { Night off-peak } \\
(7: 00 \text { pm-8:00 pm) }\end{array}$ & 2.0 & 2.1 & 5.0 & 200.0 \\
\begin{tabular}{l} 
Default values \\
\hline
\end{tabular} & 1.5 & 0.9 & 4.0 & 200.0 \\
\hline
\end{tabular}



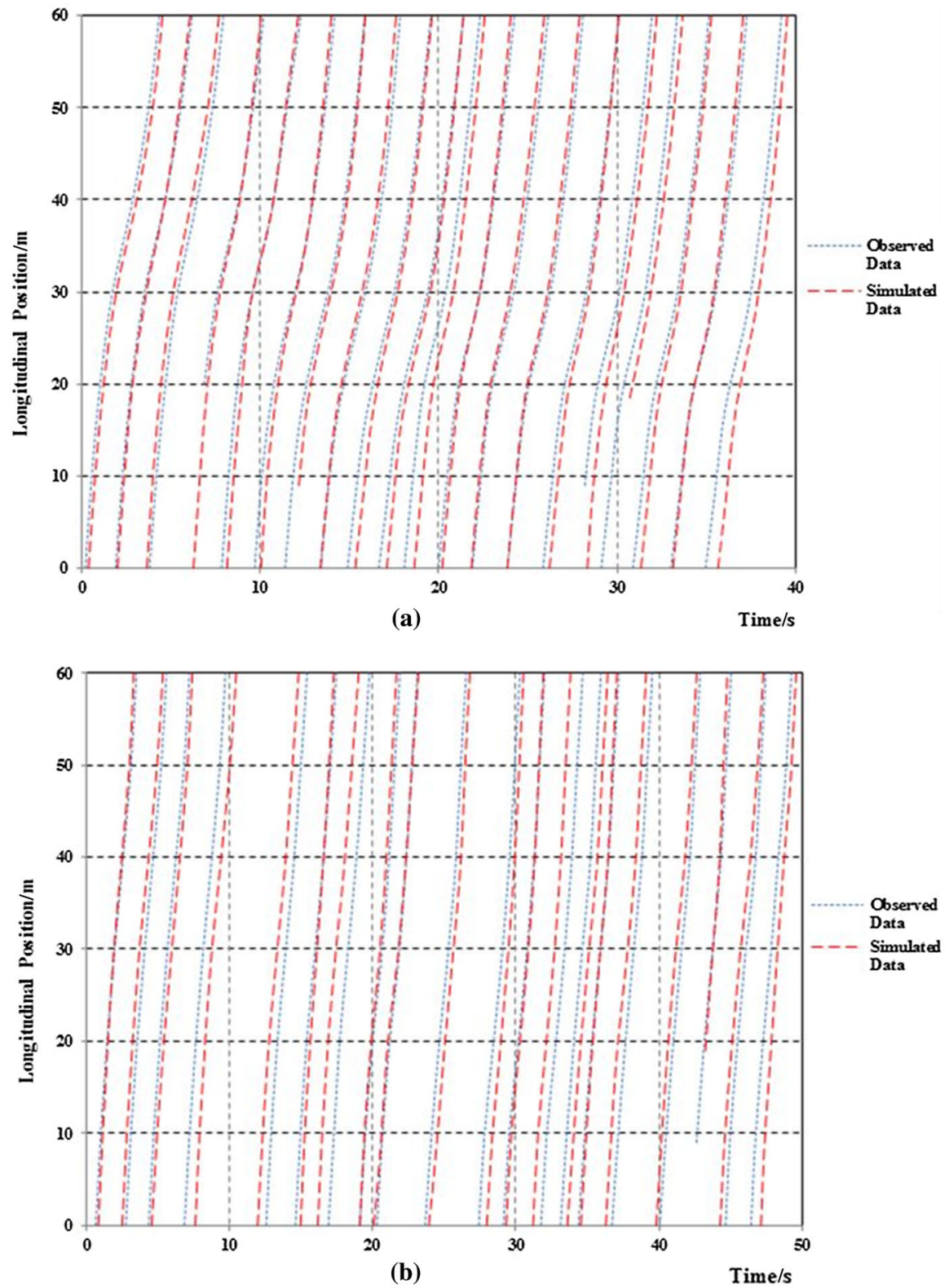

Fig. 2 The differences between the simulated and observed data in different time (a) morning peak time; (b) transitional off-peak time; (c) afternoon peak time; (d) night off-peak time

$$
U=\frac{\sqrt{\frac{1}{N} \sum_{n=1}^{N}\left(v_{s}^{n}-v_{f}^{n}\right)^{2}}}{\sqrt{\frac{1}{N} \sum_{n=1}^{N}\left(v_{s}^{n}\right)^{2}}+\sqrt{\frac{1}{N} \sum_{n=1}^{N}\left(v_{f}^{n}\right)^{2}}},
$$



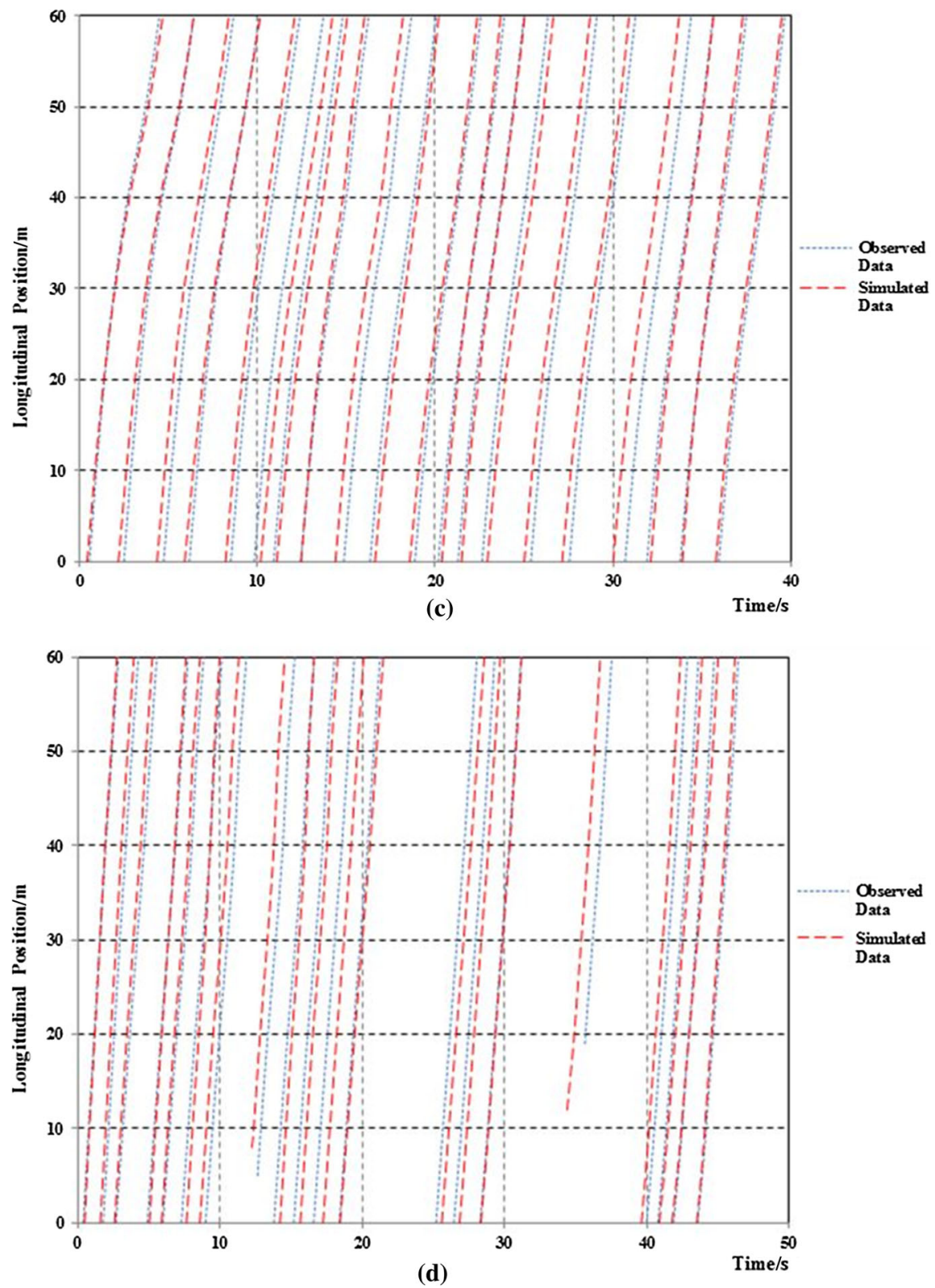

Fig. 2 continued

where $v_{s}^{n}$ represents the simulation value (speed) of the $n$th vehicle, $v_{f}^{n}$ denotes the field value (speed) of the $n$th vehicle, and $N$ is the number of vehicles observed or simulated. The comparative results based on the four time groups are aggregated in Table 3. 
Table 3 Error tests of speeds

\begin{tabular}{|c|c|c|c|c|}
\hline Time periods & $\operatorname{RMSE}(\mathrm{m} / \mathrm{s})$ & RMSPE/\% & MPE/\% & $U / \%$ \\
\hline $\begin{array}{l}\text { Morning peak } \\
(7: 00 \mathrm{am}-8: 00 \mathrm{am})\end{array}$ & 2.64 & 11.86 & 5.75 & 0.23 \\
\hline $\begin{array}{l}\text { Transitional } \\
\text { off-peak } \\
(12: 00 \mathrm{pm}-1: 00 \mathrm{pm})\end{array}$ & 3.28 & 13.73 & 6.67 & 0.26 \\
\hline $\begin{array}{l}\text { Afternoon peak } \\
(4: 00 \mathrm{pm}-5: 00 \mathrm{pm})\end{array}$ & 2.68 & 11.51 & 5.51 & 0.24 \\
\hline $\begin{array}{l}\text { Night off-peak } \\
\quad(7: 00 \mathrm{pm}-8: 00 \mathrm{pm})\end{array}$ & 3.37 & 14.19 & 7.69 & 0.28 \\
\hline Mean & 2.99 & 12.82 & 6.41 & 0.25 \\
\hline
\end{tabular}

As can be seen in Table 3, the average difference between the simulated speeds and the observed speeds in all time groups is $2.99 \mathrm{~m} / \mathrm{s}$ based on the RMSE test. For a speed limit of $110 \mathrm{~km} / \mathrm{h}(30.56 \mathrm{~m} / \mathrm{s})$, the error of $2.99 \mathrm{~m} / \mathrm{s}$ is in the acceptable range. All groups have RMSPEs of less than $15 \%$, and the mean across all vehicles is $12.82 \%$. The average MPE is positive $(6.41 \%)$, which indicates that the simulated speeds are slightly over-estimated by VISSIM compared with real speeds. Furthermore, Theil's inequality coefficient is close enough to zero. The closer the coefficient is to zero, the smaller is the difference in speeds. Accordingly, we can draw the conclusion that VISSIM is a useful traffic simulation model, which can simulate the real traffic situation reasonably well on the microscopic level and can be used in this study.

\section{Results}

\subsection{Travel Time Analysis}

\subsubsection{Impact of Traffic Flow}

The average travel time that all vehicles spent on passing through this research segment fitted with two on-ramp lane arrangements are shown in Fig. 3(a). Apparently, as the freeway traffic flow increases, the travel time for these two on-ramp configurations reveals a growing tendency in the context of a fixed percentage of HGVs. Under any traffic flow scenario, vehicles spend less average travel time on the freeway section with added lane than that with zip merging. With the growth of traffic volume, the travel time increase rate for these two on-ramp configurations both become greater. Meanwhile, the two travel time consumption gaps also become greater.

\subsubsection{Impact of HGVs}

In addition, the impacts of the proportion of HGVs on freeway mainline on travel time are compared below. The analysis will be carried out for two different cases: 1600 and $1800 \mathrm{vehs} / \mathrm{h} / \mathrm{lane}$. This is because, when the traffic volume ranges from 1600 to 


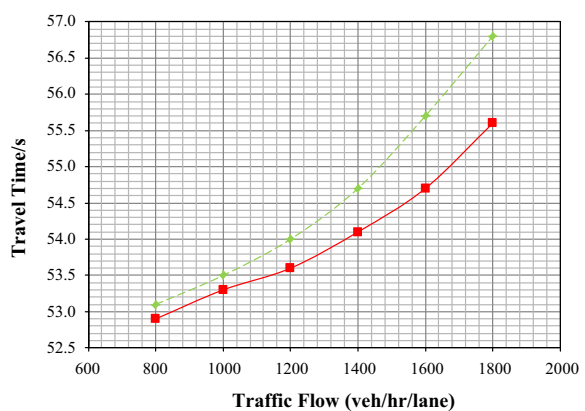

(a)

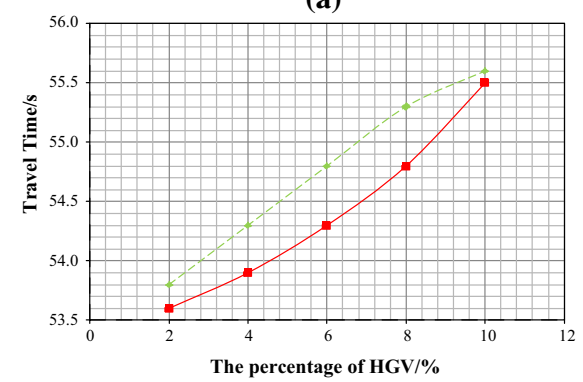

(b)

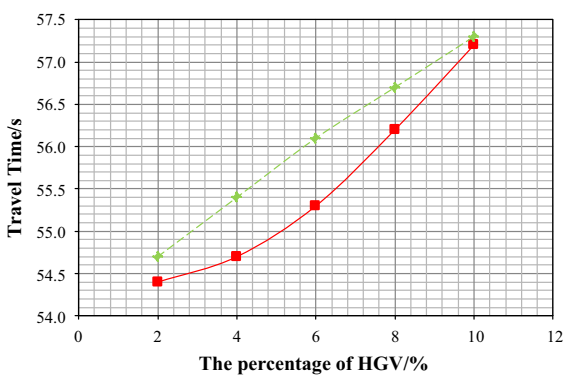

(c)

Fig. 3 (a) The relationship between travel time and traffic flow for both on-ramp lane arrangements when the real observed percentage of HGVs is 7.3\%; (b) The relationship between travel time and percentage of HGVs for both on-ramp lane arrangements when traffic volume is 1600 vehs/h/lane (LOS D); (c) The relationship between travel time and percentage of $\mathrm{HGVs}$ for both on-ramp lane arrangements when traffic volume is $1800 \mathrm{vehs} / \mathrm{h} / \mathrm{lane}$ (LOS E)

$2200 \mathrm{vehs} / \mathrm{h} / \mathrm{lane}$, the level of service (LOS) curve that depicts average speed versus traffic flow will exhibit a clear transformation. When the traffic volume is less than $1600 \mathrm{vehs} / \mathrm{h} / \mathrm{lane}$, the average vehicle speed is almost invariable. Moreover, 1600 and $1800 \mathrm{vehs} / \mathrm{h} / \mathrm{lane}$, respectively, satisfies LOS D and E. Therefore, we can more clearly distinguish the impacts of the proportion of HGVs on travel time for both on-ramps under two LOS conditions.

Through the above analysis, the relationships between travel time and the percentage of HGVs on mainline for both on-ramp lane arrangements under LOS D and E are illustrated in Fig. 3(b, c). Overall, the travel time consumed in the research segment with the two on-ramp configurations both goes up with the increase in proportion of HGVs, and under the same percentage of HGVs, the greater the traffic flow is the longer the average travel time is spent. According to Fig. 3(b) and Fig. 3(c), when the percentage of HGVs on freeway is small enough (2\%) or great enough (10\%), the difference in average travel time can be ignored. Comparatively, when the proportion of $\mathrm{HGVs}$ ranges from $4 \%$ to $8 \%$, the performance of added lane is superior to that of zip merging. This reflects the following three mechanisms. Firstly, when the number of HGVs on the freeway is small, those small cars can freely change lane and are not subject to the impact of vehicle interaction, particularly HGVs. Secondly, when the number of HGVs is in the normal range, the auxiliary lane attached to added lane can contribute to longer acceleration lane and more accommodation for those 
merging cars than zip merging. As a consequence, the whole traffic situation is more organized. Thirdly, when the proportion reaches its critical value, a large number of HGVs running along with outward lane may form a series of hindrance to vehicles so that they cannot merge or diverge as usual. Therefore, either on-ramp lane arrangement can be adopted in this case.

\subsection{Emissions Analysis}

\subsubsection{Impact of Traffic Flow}

The fuel and $\mathrm{CO}_{2}$ emissions calculated by CMEM model completely depend upon a vehicle's acceleration and speeds. However, the acceleration and speed of every vehicle are not constant in the research segment, which increases the difficulty of calculating emissions. To overcome it, we adopt the sectioning method to collect each vehicle's instantaneous speed and acceleration and calculate every vehicle's $\mathrm{CO}_{2}$ emissions in the corresponding sections using the CMEM model. Finally, all the emissions can be accumulated together. Figure 4(a) depicts the relationship between $\mathrm{CO}_{2}$ emissions for both on-ramp lane arrangements and the mainline traffic flow when the percentage of HGVs on freeway is $7.3 \%$.

As can be seen in Fig. 4(a), we can conclude that, with an increase in traffic flow, $\mathrm{CO}_{2}$ emissions for the two on-ramp lane arrangements present a logarithmic increasing tendency. In any case, vehicles travelling through the freeway section with zip merging
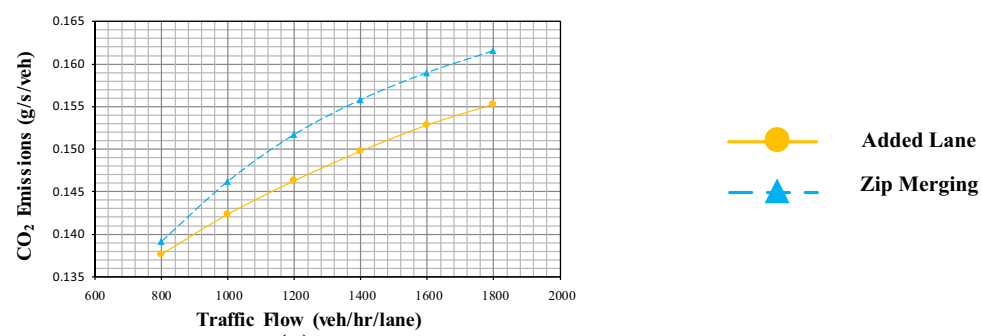

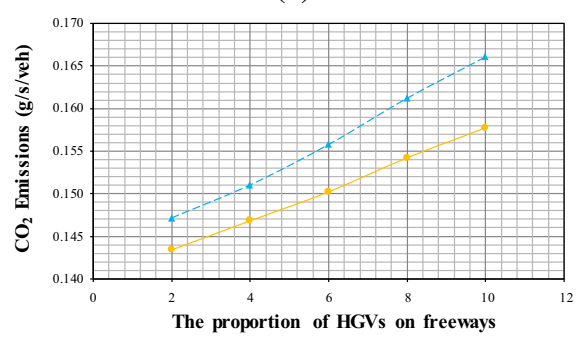

(b)

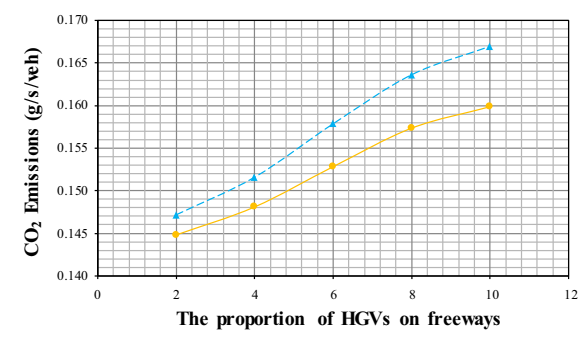

(c)

Fig. 4 (a) The relationship between $\mathrm{CO}_{2}$ emissions and traffic flow for both on-ramp lane arrangements when the real observed percentage of HGVs is 7.3\%; (b) The relationship between $\mathrm{CO}_{2}$ emissions and the proportion of HGVs for both on-ramp lane arrangements when traffic volume is 1600 vehs/h/lane (LOS D); (c) The relationship between $\mathrm{CO}_{2}$ emissions and the proportion of HGVs for both on-ramp lane arrangements when traffic volume is 1800 vehs/h/lane (LOS E) 
emit more greenhouse gases than those do under the other on-ramp lane arrangement. However, with the growth in traffic volume, the difference in $\mathrm{CO}_{2}$ emissions between the two arrangements becomes greater and the increase rates of emissions for both lane arrangements gradually diminish, which implies that vehicles in the zip merging situation undertake a higher frequency of changes in speed and acceleration.

\subsubsection{Impact of HGVs}

Overall, greenhouse gas emissions in the research segment under both on-ramp lane arrangements go up with an increase in the percentage of HGVs under any traffic flow, and under the same percentage of HGVs, the greater the traffic flow is the more greenhouse gases vehicles emit. According to Fig. 4(b), the performance in terms of $\mathrm{CO}_{2}$ emissions of the added lane is superior to that of zip merging under any proportion of HGVs. In addition, the gap between $\mathrm{CO}_{2}$ emissions for both lane arrangements is gradually magnified. Figure 4(c) shows the same variation tendency as Fig. 4(b).

To sum up, when the proportion of HGVs on freeways and the mainline traffic flow are small enough, the two on-ramp lane arrangements fail to show a significant difference in emissions. By taking the initial construction costs into account, zip merging should be chosen here. However, with the increase in the proportion of HGVs on freeways and the mainline traffic flow, the added lane has a greater ability to resist the rise of emissions.

\section{$5.3 \mathrm{CO}_{2}$ Emissions Contour Chart}

The impact analyses of two relevant factors, traffic volume and percentage of HGVs, on $\mathrm{CO}_{2}$ emissions are carried out. Towards this end, the following impact analysis procedure is followed. First, the ranges of traffic volume $\left(T_{i}\right)$ and the percentage of HGVs $\left(H_{j}\right)$ are determined and discretized. The traffic volume ranges from 800 to $1800 \mathrm{vehs} / \mathrm{h} / \mathrm{lane}$ in accordance with real-life observations, and the step is taken to be $200 \mathrm{vehs} / \mathrm{h} / \mathrm{lane}$ based on previous research [26, 27]. The proportion of HGVs is assumed to range from $2 \%$ to $10 \%$ and a $2 \%$ step is adopted. Therefore, the typical traffic volumes and percentages of HGVs are, respectively, taken to be 800, 1000 , 1 200, 1 400, 1600 and $1800 \mathrm{vehs/h/lane,} \mathrm{and} \mathrm{2 \% ,4 \% ,} \mathrm{6 \% ,8 \%} \mathrm{and} \mathrm{10 \% .} \mathrm{Then,} \mathrm{all}$ possible combinations of the two contributing factors (percentage of HGVs and traffic volume) are applied to calculate $\mathrm{CO}_{2}$ emissions for the two on-ramp lane arrangements. Figure 5 shows the two-factor-based impact analysis procedure.

Further, the $\mathrm{CO}_{2}$ emissions contour charts for the two on-ramp lane arrangements can be drawn to show the changing pattern of $\mathrm{CO}_{2}$ emissions. To do so, all 30 possible combinations of the two factors are taken into account. All points that emit the same quantity of greenhouse gases are plotted and connected using a smooth line. These charts are drawn in Fig. 6(a) and Fig. 6(b) for an added lane and zip merging respectively.

As shown in Fig. 6(a) and Fig. 6(b), the $\mathrm{CO}_{2}$ emissions will grow as the traffic volume and percentage of $\mathrm{HGVs}$ increase. These two $\mathrm{CO}_{2}$ emissions contour charts could help traffic engineers to select the most suitable combination of the percentage of $\mathrm{HGVs}$ and the traffic volume for any given $\mathrm{CO}_{2}$ emissions target. 


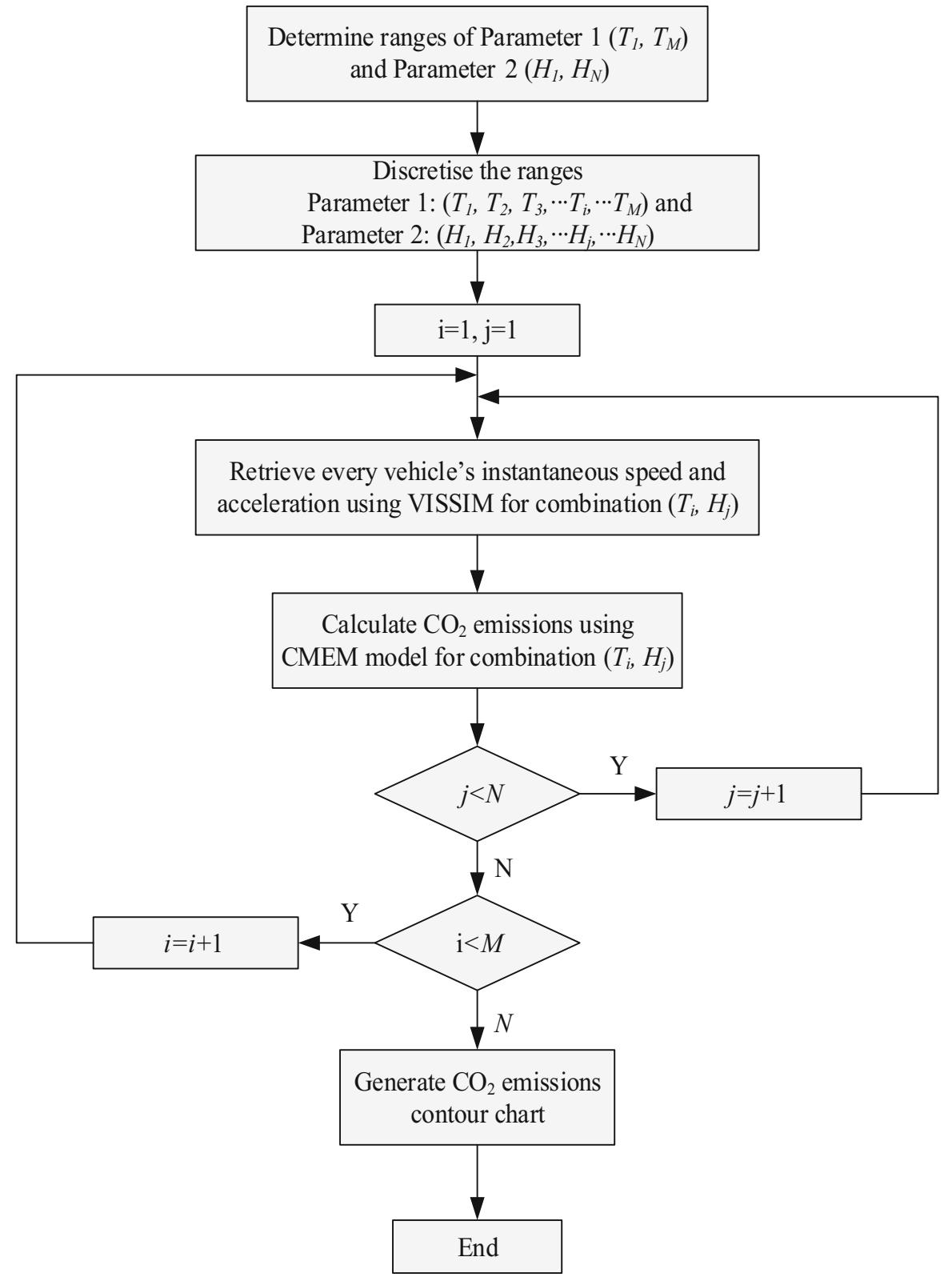

Fig. 5 Two-factor-based impact analysis procedure 


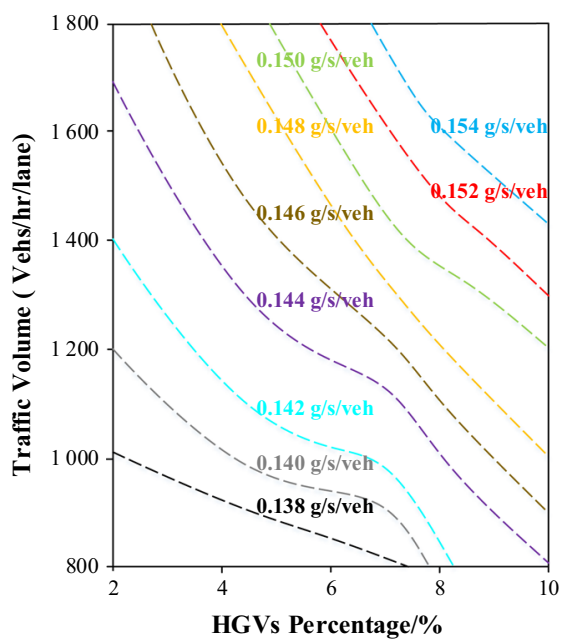

(a)

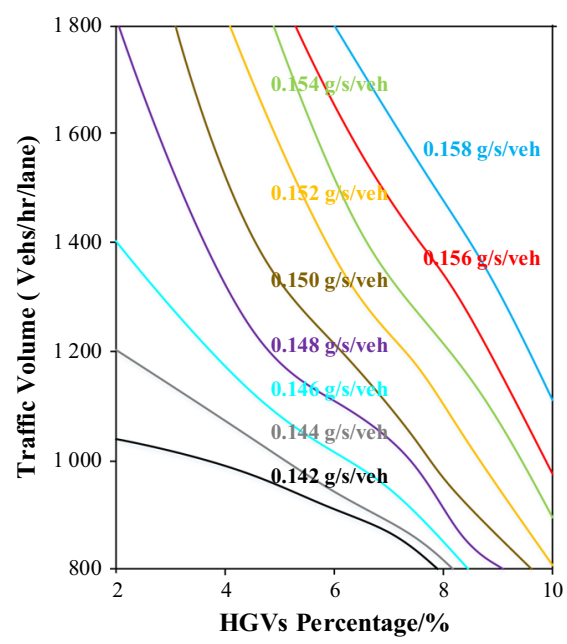

(b)

Fig. $6 \mathrm{CO}_{2}$ emissions contour chart for the (a) added lane arrangement; (b) zip merging arrangement

\section{Conclusion}

In this paper, we compared the performances of two on-ramp lane arrangements (zip merging and added lane) at the research segment in terms of travel time and $\mathrm{CO}_{2}$ emissions, in order to assist traffic engineers in choosing the appropriate on-ramp arrangement based on a given $\mathrm{CO}_{2}$ emissions target. To this end, we first recorded the real traffic trajectory at the selected site and utilized them to validate reliability of VISSIM-based simulated data. Second, the CMEM, depending upon two variables, instantaneous speed and acceleration, was applied to calculate $\mathrm{CO}_{2}$ emissions. Third, we evaluated travel time and $\mathrm{CO}_{2}$ emissions for two on-ramp lane arrangements under scenarios with traffic volumes varying from 800 to $1800 \mathrm{vehs} / \mathrm{h} / \mathrm{lane}$ in steps of 200, for an observed percentage of HGVs of $7.3 \%$. In all cases, the performance of the added lane was superior to that of the zip merging lane. Meanwhile, the average travel time and $\mathrm{CO}_{2}$ emissions for scenarios with $\mathrm{HGV}$ percentages of $2 \%, 4 \%, 6 \%, 8 \%$ and $10 \%$, respectively, and for traffic volumes of 1600 (LOS D) and 1800 (LOS E) vehs/h/lane were also compared. In regard to the travel time, for the scenarios with high traffic volumes and within a normal range of HGVs, the added lane can be a better selection; but for the cases with high traffic volumes and low or critical proportion of HGVs, either can be selected. In terms of environmental sustainability, the added lane indeed performed better than the zip merging in this study. Fourth, we provided the concept of emissions contour charts to facilitate transport agencies' simultaneous analysis of the impact of HGVs and traffic volume.

Open Access This article is distributed under the terms of the Creative Commons Attribution 4.0 International License (http://creativecommons.org/licenses/by/4.0/), which permits unrestricted use, distribution, and reproduction in any medium, provided you give appropriate credit to the original author(s) and the source, provide a link to the Creative Commons license, and indicate if changes were made. 


\section{Appendix}

Description of nomenclature used in calculating fuel and $\mathrm{CO}_{2}$ emission rates

\begin{tabular}{|c|c|c|c|c|c|}
\hline Name & Description & Unit & $\begin{array}{l}\text { Default value } \\
\text { for passenger } \\
\text { cars }\end{array}$ & $\begin{array}{l}\text { Default value } \\
\text { for HGVs }\end{array}$ & References \\
\hline$\phi$ & $\begin{array}{l}\text { Air-fuel } \\
\text { equivalence } \\
\text { ratio }\end{array}$ & - & 1.00 & 1.13 & Nam [28] \\
\hline$\lambda$ & $\begin{array}{l}\text { Lower heating } \\
\text { value }\end{array}$ & $\mathrm{J} / \mathrm{g}$ & 44000 & & Nam [28] \\
\hline$P_{a}$ & Axillary power & W & 1000 & 1500 & Nam [28] \\
\hline$\eta$ & $\begin{array}{l}\text { Engine } \\
\text { efficiency }\end{array}$ & - & 0.40 & 0.35 & Barth et al. [30] \\
\hline$Z$ & Mass & $\mathrm{kg}$ & $\begin{array}{l}\text { Depends on the } \\
\text { simulated data }\end{array}$ & & - \\
\hline$g$ & $\begin{array}{l}\text { Acceleration of } \\
\text { gravity }\end{array}$ & $\mathrm{Nm} / \mathrm{s}^{2}$ & 9.81 & & Nam [28] \\
\hline$G$ & Grade & - & Flat $=0$ & & - \\
\hline$\varepsilon$ & $\begin{array}{l}\text { Drivetrain } \\
\text { efficiency }\end{array}$ & - & 0.85 & & Barth et al. [30] \\
\hline$K_{0}$ & Constant & $\mathrm{J} / \mathrm{rev} / \mathrm{l}$ & 200 & & Barth et al. [30] \\
\hline$V$ & $\begin{array}{l}\text { Engine } \\
\text { displacement }\end{array}$ & $\mathrm{L}$ & $\begin{array}{l}\text { Depends on the } \\
\text { simulated data }\end{array}$ & & - \\
\hline$\theta$ & Constant & - & 0.8159 & & Nam [28] \\
\hline $\bar{r}$ & Constant & - & 10 & & Nam [28] \\
\hline$\underline{r}$ & Constant & - & 2 & & Nam [28] \\
\hline$v_{h}$ & Constant & $\mathrm{m} / \mathrm{s}$ & 35 & & Barth et al. [30] \\
\hline$\rho$ & Air density & $\mathrm{kg} / \mathrm{m}^{3}$ & 1.247 & & $\begin{array}{l}\text { Mannering } \\
\text { et al. [29] }\end{array}$ \\
\hline$C_{d}$ & $\begin{array}{l}\text { Drag } \\
\text { coefficient }\end{array}$ & - & 0.3 & 0.5 & $\begin{array}{l}\text { Mannering } \\
\text { et al. [29] }\end{array}$ \\
\hline$A$ & Frontal area & $\mathrm{m}^{2}$ & 2 & 3 & Austroads [2] \\
\hline$e_{0}$ & Mass factor & - & 0.1 & & Nam [28] \\
\hline$\mu$ & Constant & - & 1.85 & & Nam [28] \\
\hline$A_{r}\left(\mathrm{CO}_{2}\right)$ & Constant & - & 44 & & Nam [28] \\
\hline$A_{r}(\mathrm{CO})$ & Constant & - & 28 & & Nam [28] \\
\hline$A_{r}(\mathrm{C})$ & Constant & - & 12 & & \\
\hline$c_{1}$ & Constant & - & 0.01 & & $\begin{array}{l}\text { Mannering } \\
\text { et al. [29] }\end{array}$ \\
\hline
\end{tabular}




\begin{tabular}{|c|c|c|c|c|c|}
\hline Name & Description & Unit & $\begin{array}{l}\text { Default value } \\
\text { for passenger } \\
\text { cars }\end{array}$ & $\begin{array}{l}\text { Default value } \\
\text { for HGVs }\end{array}$ & References \\
\hline$c_{2}$ & Constant & $\mathrm{m} / \mathrm{s}$ & 44.73 & & $\begin{array}{l}\text { Mannering } \\
\text { et al. [29] }\end{array}$ \\
\hline$c_{3}$ & Constant & - & 0.0065 & & $\begin{array}{l}\text { Mannering } \\
\text { et al. [29] }\end{array}$ \\
\hline$c_{4}$ & Constant & - & 1.25 & & $\begin{array}{l}\text { Mannering } \\
\text { et al. [29] }\end{array}$ \\
\hline$c_{5}$ & Constant & - & 0.4074 & & $\begin{array}{l}\text { Mannering } \\
\text { et al. [29] }\end{array}$ \\
\hline$c_{6}$ & Constant & - & 0.1174 & & $\begin{array}{l}\text { Mannering } \\
\text { et al. [29] }\end{array}$ \\
\hline$c_{7}$ & Constant & - & 0.01 & & $\begin{array}{l}\text { Mannering } \\
\text { et al. [29] }\end{array}$ \\
\hline$c_{8}$ & Constant & $\mathrm{g} / \mathrm{s}$ & 0.0049 & & $\begin{array}{c}\text { Mannering } \\
\text { et al. [29] }\end{array}$ \\
\hline
\end{tabular}

\section{References}

[1] Qu, X., Zhang, J., Wang, S.: On the stochastic fundamental diagram for freeway traffic: model development, analytical properties, validation, and extensive applications. Transp. Res. Part B. 104, 256-271 (2017)

[2] Austroads: Freeway Design Parameters for Fully Managed Operations. Austroads, Sydney (2009)

[3] Mergia, W., Eustace, D., Chimba, D., Qumsiyeh, M.: Exploring factors contributing to injury severity at freeway merging and diverging locations in Ohio. Accid. Anal. Prev. 55, 202-210 (2013)

[4] Bonneson, J.: Recommended Ramp Design Procedures for Facilities Without Frontage Roads, 1st edn. Texas Transportation Institute, Texas A \& M University System, College Station (2002)

[5] Jacobson, L.: Ramp Management and Control Handbook, 1st edn. Federal Highway Administration, Washington (2006)

[6] Louah, G., Daucher, D., Conde-Céspedes, P., Bosc, F., Lhuillier, J.: Traffic operations at an entrance ramp of a suburban freeway first results. Procedia Soc. Behav. Sci. 16, 162-171 (2011)

[7] Neudorff, L.: Freeway Management and Operations Handbook, 1st edn. Federal Highway Administration, Washington (2006)

[8] Qu, X., Wang, S.: Long distance commuter lane: a new concept for freeway traffic management. Comput. Aided Civ. Infrastruct. Eng. 30(10), 815-823 (2015)

[9] Xu, Z., Wei, T., Easa, S., Zhao, X., Qu, X.: Modeling relationship between truck fuel consumption and driving behavior using data from internet of vehicles. Comput. Aided Civ. Infrastruct. Eng. 33(3), 209-219 (2018)

[10] Barth, M., An, F., Norbeck, J., Ross, M.: Modal emissions modeling: a physical approach. Transp. Res. Rec. J. Transp. Res. Board 1520, 81-88 (1996)

[11] Hung, W., Tong, H., Cheung, C.: A modal approach to vehicular emissions and fuel consumption model development. J. Air Waste Manag. Assoc. 55(10), 1431-1440 (2005)

[12] Norowitz, J.L.: Air Quality Analysis for Urban Transportation Planning. MIT Press, Cambridge (1982)

[13] Barlow, T., Boulter, P.: Emission Factors 2009, 1st edn. TRL, Wokingham (2009)

[14] Rakha, H., Ahn, K., Trani, A.: Development of VT-Micro model for estimating hot stabilized light duty vehicle and truck emissions. Transp. Res. Part D Transp. Environ. 9(1), 49-74 (2004)

[15] Bie, Y., Cheng, S., Easa, S., Qu, X.: Stop Line set back at a signalized roundabout: a novel concept for traffic operations. J. Transp. Eng. 142(3), 05016001 (2016)

[16] Zhen, L., Wang, K.: A stochastic programming model for multi-product oriented multi-channel component replenishment. Comput. Oper. Res. 60, 79-90 (2015) 
[17] Zhen, L., Wang, K., Liu, H.: Disaster relief facility network design in metropolises. IEEE Trans. Syst. Man Cybern. Syst. 45(5), 751-761 (2015)

[18] Nie, Y., Li, Q.: An eco-routing model considering microscopic vehicle operating conditions. Transp. Res. Part B Methodol. 55, 154-170 (2013)

[19] Benekohal, R.F.: Procedure for validation of microscopic traffic flow simulation models. Transp. Res. Part B 35, 293-312 (1989)

[20] Bham, G., Benekohal, R.: A high fidelity traffic simulation model based on cellular automata and car-following concepts. Transp. Res. Part C Emerg. Technol. 12(1), 1-32 (2004)

[21] Jin, S., Qu, X., Zhou, D., Xu, C., Ma, D., Wang, D.: Estimating cycleway capacity and bicycle equivalent unit for electric bicycles. Transp. Res. Part A Policy Pract. 77, 225-248 (2015)

[22] Jin, S., Wang, D., Huang, Z., Tao, P.: Visual angle model for car-following theory. Physica A 390(11), 1931-1940 (2011)

[23] Kuang, Y., Qu, X., Wang, S.: A tree-structured crash surrogate measure for freeways. Accid. Anal. Prev. 77, 137-148 (2015)

[24] Qu, X., Wang, S., Zhang, J.: On the fundamental diagram for freeway traffic: a novel calibration approach for single-regime models. Transp. Res. Part B Methodol. 73, 91-102 (2015)

[25] Qu, X., Yang, Y., Liu, Z., Jin, S., Weng, J.: Potential crash risks of expressways on-ramps and offramps: a case study in Beijing, China. Saf. Sci. 70, 58-62 (2014)

[26] Meng, Q., Qu, X., Yong, K., Wong, Y.: QRA model-based risk impact analysis of traffic flow in urban road tunnels. Risk Anal. 31(12), 1872-1882 (2011)

[27] Styles, T., Luk, J.: Zip Merging from Freeway Entry Ramps in Victoria, 1st edn. VicRoads, Kew (2006)

[28] Nam, E.: Proof of concept investigation for the physical emission rate estimator for MOVES. Technical report (2003)

[29] Mannering, F.L., Kilareski, W.P., Washburn, S.S.: Principles of highway engineering and traffic analysis. John Wiley \& Sons, New York (2005)

[30] Barth, M., An, F., Younglove, T., Scora, G., Levine, C., Ross, M., Wenzel, T.: Development of a comprehensive modal emissions model. Tech. rep., National Cooperative Highway Research Program (2000) 